Electrical \& Computer Engineering: An International Journal (ECIJ) Vol.7, No.1/2, June 2018

\title{
GRID SIDE CONVERTER CONTROL IN DFIG BASED WIND SYSTEM USING ENHANCED HYSTERESIS CONTROLLER
}

\author{
M.Ramesh and T.R.Jyothsna \\ Department of Electrical and Electronics Engineering \\ Andhra University, Visakhaptnam, Andhra Pradesh, India
}

\begin{abstract}
The standard grid codes suggested, that the wind generators should stay in connected and reliable active and reactive power should be provided during uncertainties. This paper presents an independent control of Grid Side Converter (GSC) for a doubly fed induction generator (DFIG). A novel GSC controller has been designed by incorporating a new Enhanced hysteresis comparator (EHC) that utilizes the hysteresis band to produce the suitable switching signal to the GSC to get enhanced controllability during grid unbalance. The EHC produces higher duty-ratio linearity and larger fundamental GSC currents with lesser harmonics. Thus achieve fast transient response for GSC. All these features are confirmed through time domain simulation on a 15 KW DFIG Wind Energy Conversion System (WECS).
\end{abstract}

\section{KEYWORDS}

WECS, DFIG, EHC, Hysteresis band

\section{INTRODUCTION}

Over the past several years wind generation resource has been one of the significant renewable technologies with a rapid growth rate all over the world. The DFIG based WECS shown in Fig.1, has increased popularity in recent years when compared to fixed-speed electrical generators. A variable speed DFIG in a wind system can deliver maximum power and can control active and reactive power by the integration of back to back power electronic converters; also, the lower power rating of the rotor results in a lesser cost of the converter components [1]. The control of active power and the $V_{d c}$ across two bridges is maintained with a slight deviation from the nominal value for an $\mathrm{AC}$ drive and the importance of the uncertainty parameters and non linear behavior discussed in [2-9]. The DM technique has been implemented to provide the control of the DC to AC conversion of a UPS system in [9]. Reduction of harmonics at lower frequencies and suppression of unwanted sub-harmonics has been obtained using DM approach in [10]. A synchronization technique is developed for static delta modulated PWM inverters and the performance of the adaptive filter is presented in [11]-[12]. The latter eliminates the frequency modulation inherent in the delta modulated inverter as well as obtains balanced phase voltages. The work presented in this paper extends and modifies the control techniques [11]-[14] and has been applied to a $15 \mathrm{~kW}$ DFIG based WECS. This article presents a novel approach for the 
Electrical \& Computer Engineering: An International Journal (ECIJ) Vol.7, No.1/2, June 2018

implementation of GSC control. The controllers developed can regulate the $V_{d c}$, obtain a wider range of GSC output voltage magnitude and enhance its power factor. Assuming that the stator quantities are in stable condition and maintain constant $V_{d c}$. The control of GSC depend on the EHC technique, which supplies the hysteresis band to the integrator inside the $\mathrm{EHC}$ as input, to produce the suitable switching signal to the GSC. The EHC technique has the features of higher duty-ratio linearity as well as maximum GSC fundamental output voltage.

This paper will be categorized as follows. First, Section II analyzes the Modeling of the DFIG, along with GSC. Then in Section III, the control strategy of GSC is developed. In section IV simulation results are presented. Finally, Section V summarizes the conclusions.

\section{DYNAMIC MODEL OF DFIG}

Fig.1 clearly depicts the overall schematic diagram of DFIG based WECS consisting of RSC and GSC converters [1].

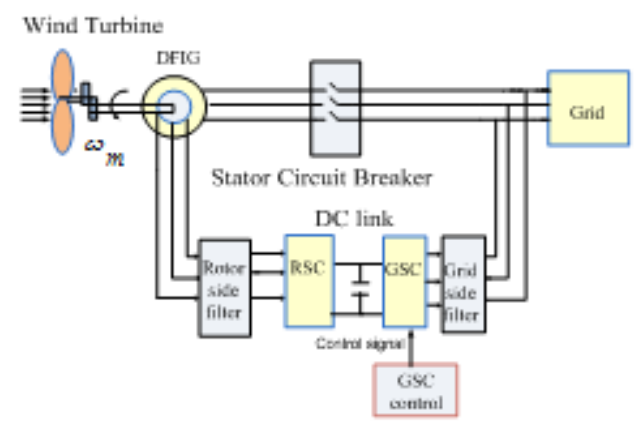

Fig.1. Schematic Diagram of DFIG Based WECS

The $15 \mathrm{~kW}$ DFIG wind system has been modeled in generating mode under normal conditions and the simulation results are presented in Section IV.D. It has been observed that, there are severe oscillations in the $V_{d c}$ and the grid currents and, to mitigate these disturbances, an independent control model of back to back converters has been established in this paper. The primary aim of the GSC has been to increase the range of duty-ratio and thereby obtain improvement in the amplitude of GSC output voltage as well as obtain ripple free GSC currents.

\section{A. Mathematical modeling of GSC}

The schematic diagram of GSC topology shown in Fig. 3 consists of six controlled power switches, grid side filter and grid. RSC controller maintains the constant $V_{d c}$ and is fed to the GSC. The output of the GSC is filtered through grid side filter and then connected to the grid [1] and modeling equations are presented in equation (1) and equation (2).

Grid Side Converter equations:

$$
V_{a b c f}=R_{g} I_{a b c g}+L_{g}\left(\frac{d I_{a b c g}}{d t}\right)+V_{a b c g}
$$


Electrical \& Computer Engineering: An International Journal (ECIJ) Vol.7, No.1/2, June 2018

Grid Side Converter state equations:

$$
\frac{d I_{a b c g}}{d t}=\frac{\left(V_{a b c f}\right)}{L_{g}}-\left(\frac{R_{g}}{L_{g}}\right) I_{a b c g}-\frac{V_{a b c g}}{L_{g}}
$$

Where

$V_{a b c f} \quad$ Three phase GSC output voltages

$V_{a b c g} \quad$ Three phase grid voltages

$I_{a b c g} \quad$ Three phase grid currents

$R_{g} \quad$ Grid side filter Resistance

$L_{g} \quad$ Grid side filter Inductance

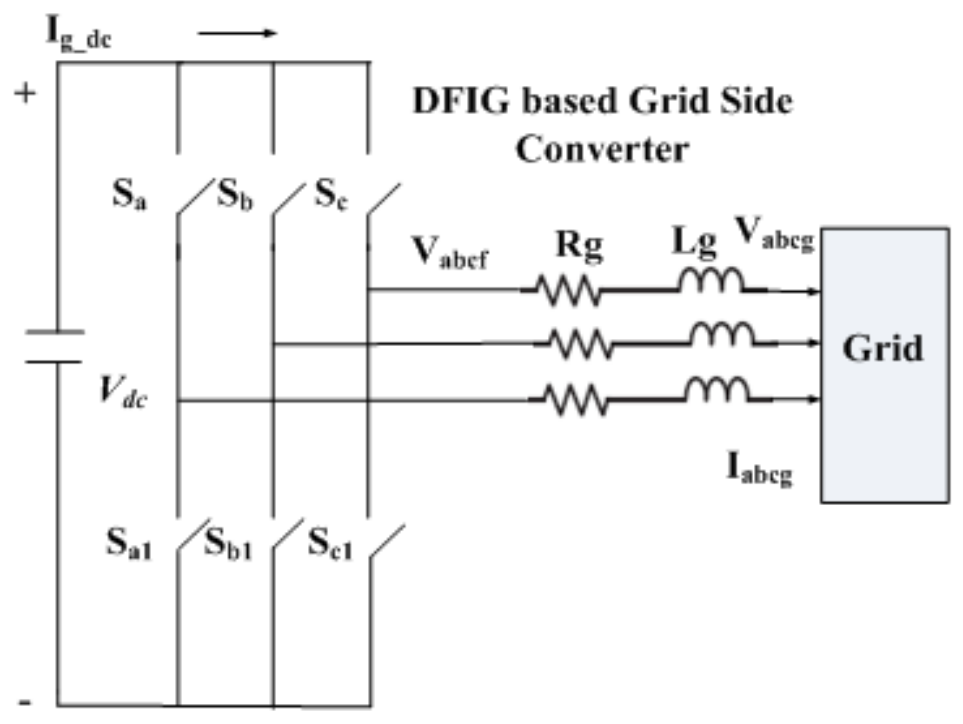

Fig.2 Schematic diagram of GSC

\section{INDEPENDENT CONTROL OF GSC}

Hysteresis Comparator (HC) technique [12], [13] shown in Figs. 3 and 4, basically compares the carrier voltage $V_{d c r e f}$ against the control voltage $V_{c s}$, to generate the error signal known as the hysteresis band; with error boundaries $\pm \Delta V_{k}$ representing the high and low levels of the hysteresis comparator. $x, y$ and $z$ are control signal slope points. $T_{o}$ is the starting point of the switching cycle, $T_{o n}$ and $T_{\text {off }}$ are turn on and turn off periods respectively of the complete cycle. The HC then processes the error signal to generate a control signal $V_{s}$, which is used to drive the GSC.

However, the technique has drawback with a poor reduction in harmonics, a lesser range of the duty-ratio, which results in a decrease in the GSC fundamental output voltage component. Hence, a modified control strategy with variable integrating slope called as the Enhanced Hysteresis Comparator (EHC) has been proposed here. 
Electrical \& Computer Engineering: An International Journal (ECIJ) Vol.7, No.1/2, June 2018

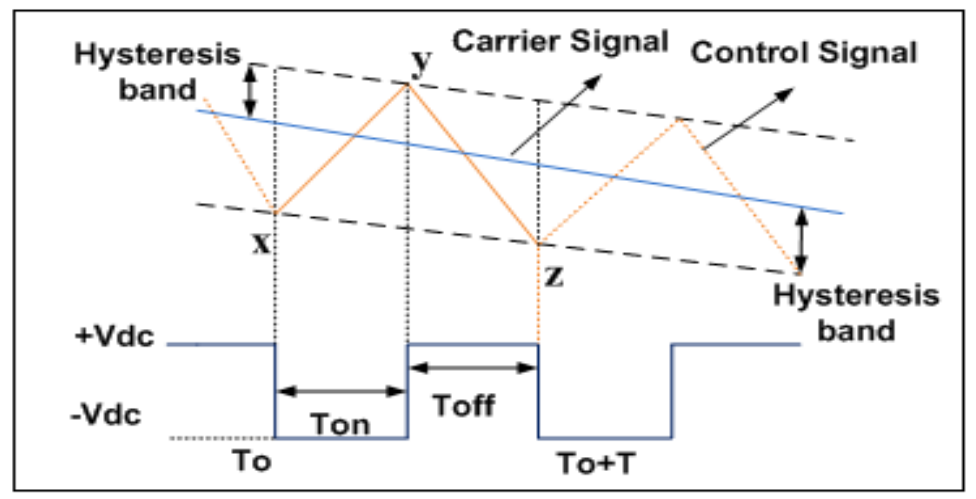

Fig.3 Basic diagram of Hysteresis comparator Technique

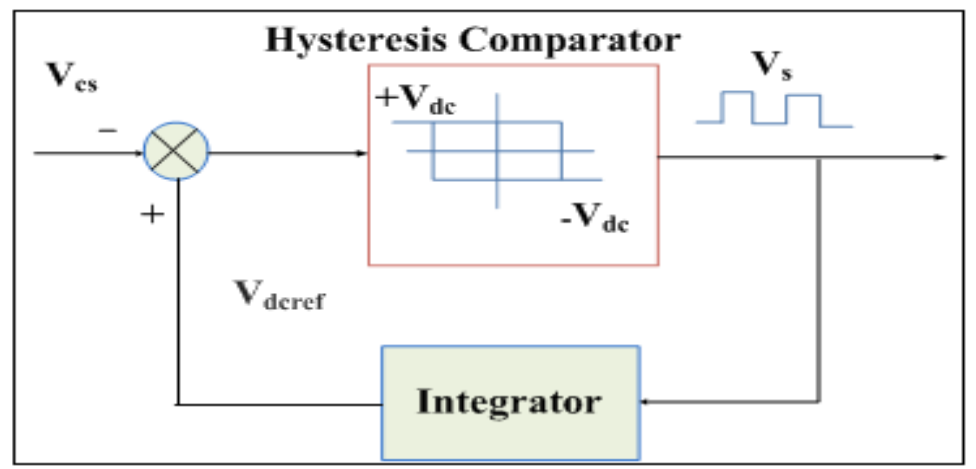

Fig.4 Hysteresis comparator technique

$V_{\text {dcref }}$ is supplied as input to the integrator of the control feedback loop to obtain a variable slope integrator which is shown in Fig.5. This slope contains the information of the $V_{d c r e f}$ and the $V_{s}$ which then follows the $V_{\text {dcref }}$ very quickly. This results in the reduction of GSC output voltage harmonics, an increase in the GSC output fundamental component, and achievement of faster response. The goal of the EHC is to adjust the output of the integrator and the error signal is processed through $\mathrm{HC}$ to generate the switching signal, which acts as the pulse signal to the GSC.

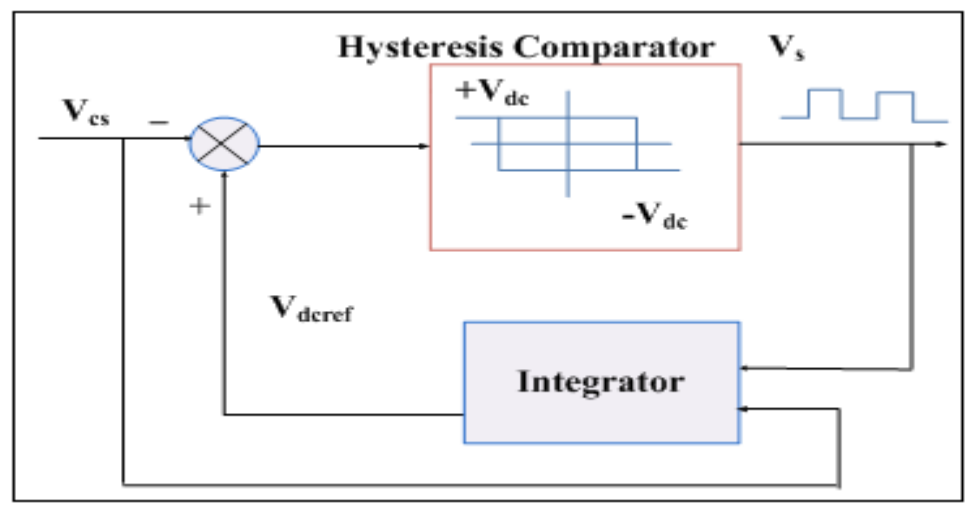

Fig.5 Enhanced Hysteresis comparator technique 
Electrical \& Computer Engineering: An International Journal (ECIJ) Vol.7, No.1/2, June 2018

The DC link voltage $V_{d c}$ is fed as input to the EHC controller as control voltage $V_{c s}$ which is dependent on the $V_{d c}$. $V_{c s}$ and $V_{d c r e f}$ are compared and fed as input to EHC where $V_{d c r e f}$ oscillates between $V_{c s} \pm \Delta V_{k}$. When the control signal $V_{s}$ which is the output of the EHC, reaches high level $+\Delta V_{k}$ it turns on the power switch in the GSC. This output signal $V_{s}$ as well as the control voltage $V_{c s}$ are fed to the input terminal of the integrator whose output $V_{d c r e f}$ is compared against the control signal $V_{c s}$ and the output $V_{s}$ now becomes $-\Delta V_{k}$ from the natural behavior of hysteresis comparator; then the value of $V_{d c r e f}$ depends on the input fed to integrator which is $V_{c s}-\Delta V_{k}$. This is compared against $V_{c s}$ and now $V_{s}$ again reaches a high level $+\Delta V_{k}$, then a switching cycle is completed. From the theoretical analysis of hysteresis comparator [8]-[10], duty-ratio is calculated based on hysteresis band $\Delta V_{k}$, switching period $T$ and slope of the $V_{c s}$ and governing equations of the controller are from (3) to (6) as follows

From above discussions, the duty-ratio in IHC controller of GSC can be given as:

$$
D_{I H C}=\frac{1}{2}+\frac{V_{c s}}{2 V_{d c}}
$$

Input current of GSC in terms of duty-ratio is given as

$$
I_{g_{-} d c}=I_{a g} D_{a o}+I_{b g} D_{b o}+I_{c g} D_{c o}
$$

Here, $V_{c s}$ is specified for one phase and other two-phase quantities are displaced by $120^{\circ}$ respectively and $V_{\max }$ is taken as modulation index times $V_{d c}[1]$ and modulation index is given as ratio of $V_{d c}$ to $V_{d c r e f}$.

$$
V_{c s a}=V_{\max } \sin (\omega t)
$$

Similarly, the GSC side output voltage is given for one phase and other two phase voltages are separated by $120^{\circ}$ respectively.

$$
V_{a f}=\frac{1}{2} V_{\max }\left(2 D_{a o}-1\right) \sin (\omega t)
$$

where

$D_{a o}$ duty-ratio of phase A

$V_{a o}$ GSC output voltage in phase A

The overall control implementation diagram is presented in Fig. 6. The DC link voltage $V_{d c}$ is fed as a control voltage for the GSC which is then controlled by EHC technique incorporated in to the GSC controller. In the proposed EHC, $V_{c s}$ is compared with $V_{d c r e f}$ and difference is fed to the hysteresis comparator to generate the triggering signal for the GSC and again $V_{c s}$ and hysteresis band are fed as inputs to the integrator to generate $V_{d c r e f}$. The proper triggering signal expressed in terms of the duty-ratio can significantly reduce the harmonics in GSC outputs. 
Electrical \& Computer Engineering: An International Journal (ECIJ) Vol.7, No.1/2, June 2018

\section{SIMULATION RESULTS}

In this paper, the proposed DFIG based WECS system has been simulated for a $15 \mathrm{KW}, 380 \mathrm{~V}$ using MATLAB R2010a. In Fig.6 the schematic diagram of the implemented system is illustrated and the specifications of the system are presented in Table I. In the system, the DFIG is operated in generating mode with a negative slip of 0.25 , its synchronous speed is $314 \mathrm{rad} / \mathrm{sec}$ and the rotor has been referred to the stator. The stator active and reactive power into the grid were considered as $P_{s}=15 \mathrm{~kW}$ and $Q_{s}=0.0 \mathrm{kVar}$, respectively. The nominal value of $V_{d c}$ is 200 $\mathrm{V}$ and SPWM with a switching frequency of $3 \mathrm{kHz}$ are considered for GSC. The performance of the DFIG-based grid connected WECS with presence of controller is simulated under variation in dip in grid voltage and performance of the system with and without a controller. Some of the important results presented here are noted in terms of $V_{d c}$, GSC output currents for three phases $\left(I_{a b c g}\right)$, active and reactive power transfer through the grid $\left(P_{g}, Q_{g}\right)$ during different dynamic conditions.

Due to non-linear behavior of the parameters, ripples are present in $V_{d c}$ on the grid side for the system without a controller, as shown in simulation results of Section IV.C. The uncertainties present in $V_{d c}$ create harmonics in GSC fundamental output voltage and currents. Hence, EHC controller is proposed for the GSC in which $V_{d c}$ is compared with $V_{d c r e f}$ and difference is fed to the EHC controller to generate the hysteresis band-triggering signal for the GSC; then the hysteresis band and $V_{d c}$ are fed as inputs to the integrator to generate $V_{d c r e f}$. The switching signals expressed in terms of duty-ratio can drastically reduce the harmonics in GSC outputs. The fundamental component of GSC output voltage and currents will be also increased. Finally, this controller is capable of achieving the constant $V_{d c}$, smooth GSC output currents and also reduction in oscillations in active and reactive powers at grid side.

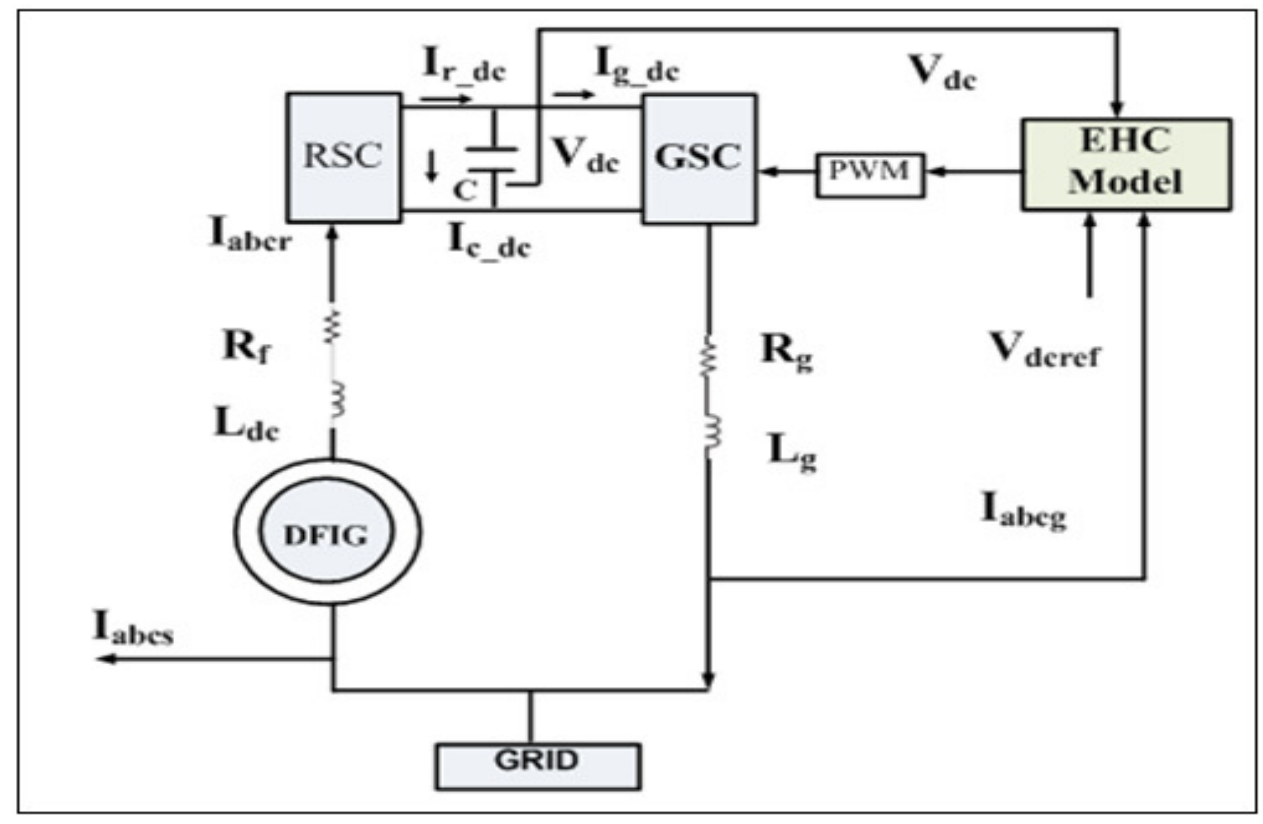

Fig.6 Schematic diagram of the implemented WECS 


\section{A. Step change in DC link Voltage Reference}

Fig.7 validates the performance of GSC controller for step variation in $V_{d c r e f}$. It can be observed that the change is initiated between the instants $0.2 \mathrm{~s}$ and $0.3 \mathrm{~s}$ as well as $0.35 \mathrm{~s}$ and $0.45 \mathrm{~s}$, respectively. The step increase of the $V_{d c r e f}$ value from $203 \mathrm{~V}$ to $210 \mathrm{~V}$ and a decrease from 203 to $180 \mathrm{~V}$, leads to the change in $V_{d c}$. The reduction in $V_{d c}$, decreases the GSC output currents and also affect the grid side active and reactive power, the results of which are shown Fig.7 (a) to (h).

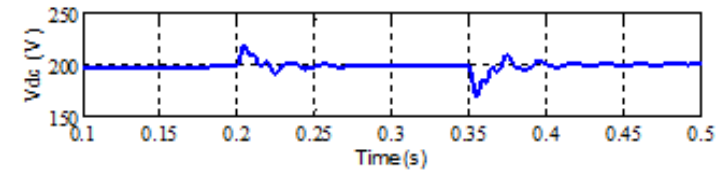

a)

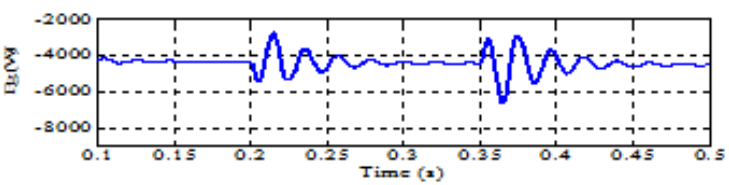

b)

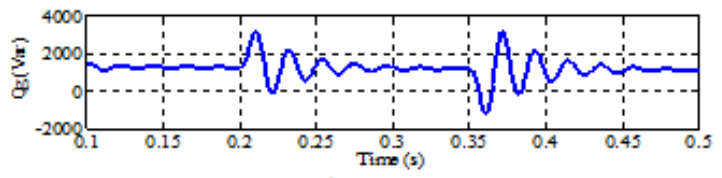

c)

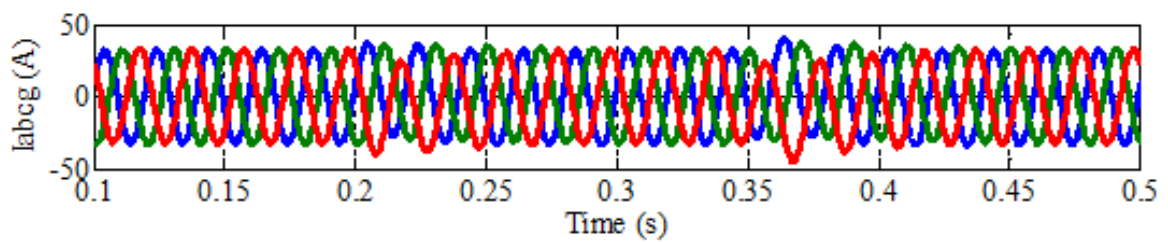

d)

Fig.7. Simulation results under step change in DC link voltage reference. (a) DC link voltage $\left(V_{d c}\right)$. (b) Grid side active power $\left(P_{g}\right)$. (c) Grid side reactive power $\left(Q_{g}\right)$. (d) GSC output currents

\section{B. Voltage Dip behavior of DFIG}

The performance of the proposed control methodology for GSC has been verified during and after a voltage dip across the grid. The control technique limits the high currents with the GSC staying connected during and after the fault. The importance of the proposed control technique is illustrated, by simulating the DFIG for a dip in voltage of $6 \%$ between $0.2 \mathrm{~s}$ and $0.3 \mathrm{~s}$. The output voltage across the GSC is shown in Fig.8. It can be observed from Fig.8 that the voltage remains below the rated voltage during voltage dip. After the removal of the disturbance, the controllers recover the system back to the normal mode and the variations under dip in grid voltage are shown in Fig.8 (a) to (d). By observing the simulation results, it can be concluded that the selected control parameters for the GSC can be obtained under $6 \%$ dip in grid voltage when independent controller is used. Hence, the time domain results to heavy disturbances are used to demonstrate the satisfactory performance of the system over a wide operating range. 
Electrical \& Computer Engineering: An International Journal (ECIJ) Vol.7, No.1/2, June 2018

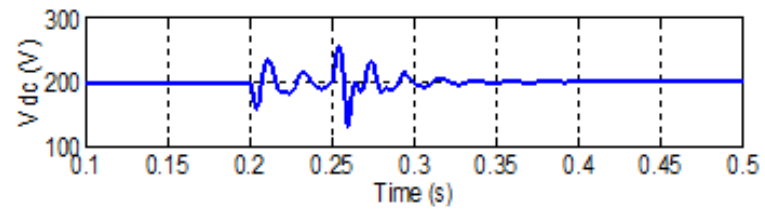

a)

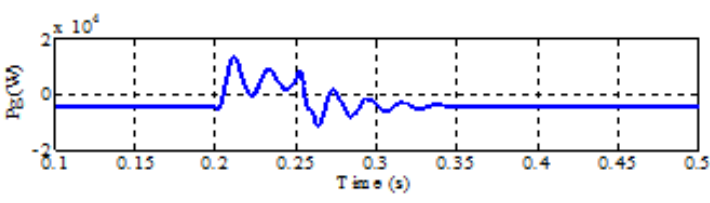

b)

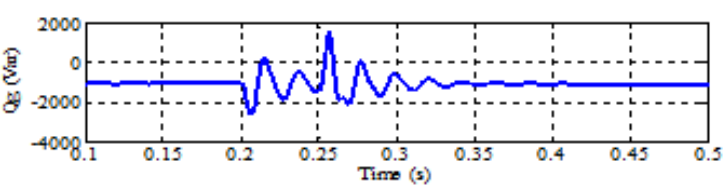

c)

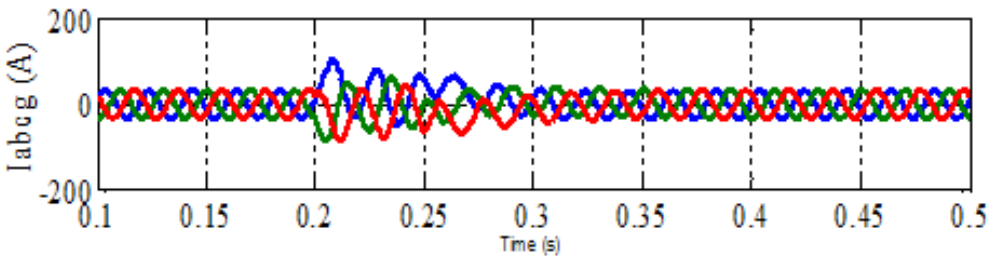

d)

Fig.8. Simulation results under dip in grid voltage. (a) DC link voltage $\left(V_{d c}\right)$. (b) Grid side active power $\left(P_{g}\right)$. (c) Grid side reactive power $\left(Q_{g}\right)$. (d) GSC output currents $\left(I_{a b c g}\right)$.

\section{Comparison of performance in DFIG based WTG with and without a controller}

As can be seen from Fig.9, this case study is presented to show the comparison between with and without a controller for the GSC, which exhibit significant oscillations and harmonics

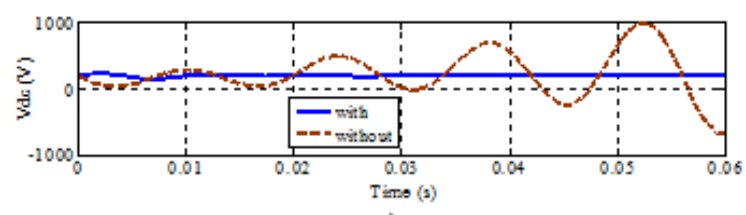

a)
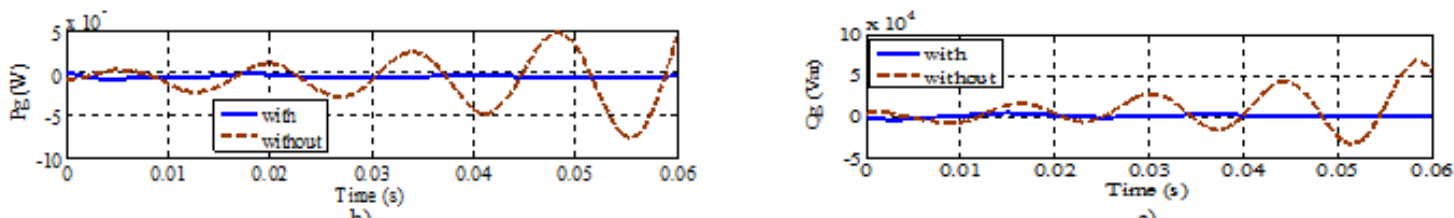

b)

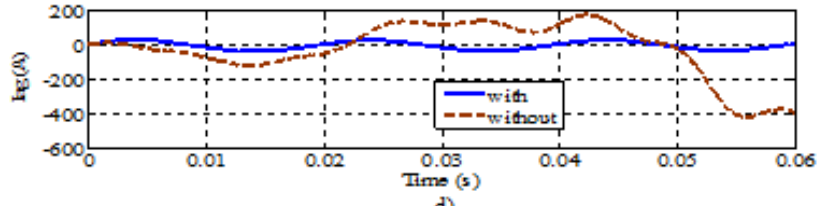

d)

Fig.9. Simulation results under with and without controller. (a) DC link voltage $\left(V_{d c}\right)$. (b) Grid side active power $\left(\mathrm{P}_{\mathrm{g}}\right)$. (c) Grid side reactive power $\left(Q_{g}\right)$. (d) GSC output current in phase A $\left(I_{a g}\right)$. 
Electrical \& Computer Engineering: An International Journal (ECIJ) Vol.7, No.1/2, June 2018

From Fig.9 (a) it is found that the $V_{d c}$ value is oscillating between $+400 \mathrm{~V}$ to $-500 \mathrm{~V}$ and the GSC output currents are not settled at the desired value. When the auxiliary controller for the GSC is enabled, the $V_{d c}$ is controlled immediately and $V_{d c}$ value is settled at $200 \mathrm{~V}$. As a result, as shown in Fig.9 (b) and (d), the GSC output current, its active and reactive power oscillations are reduced under the proposed control strategy and can significantly enhance the control and operation of DFIG system.

Table. I DFIG WECS PARAMETERS

\begin{tabular}{cc}
\hline \hline DFIG & $15 \mathrm{~kW}$ \\
\hline Stator voltage & $380 \mathrm{~V}$ \\
Rotor voltage & $80 \mathrm{~V}$ \\
DC link Voltage & $200 \mathrm{~V}$ \\
Rotor side filter Inductor & $8 \mathrm{mH}$ \\
Rotor side filter Resistor & $10 \mathrm{~m} \Omega$ \\
Grid side filter Inductor & $4 \mathrm{mH}$ \\
Grid side filter Resistor & $10 \mathrm{~m} \Omega$ \\
\hline \hline
\end{tabular}

\section{CONCLUSION}

In this paper, A novel and reinforced control strategy has been investigated in detail for a DFIG based WECS under different system conditions. During different transient conditions, the control objectives are focused on how to enhance the performance of DFIG. The proposed EHC controller for GSC is capable of achieving good control during grid voltage unbalance. The advantages include a wider range of duty-ratio and lesser harmonics in fundamental GSC current components. The EHC strategy can also achieve fast transient response for the GSC in grid-tied WECS. Therefore, the proposed control strategy gives comparatively less complexity during implementation of the system. The simulation results effectively demonstrate the correctness of the developed model and their capability to alleviate the disturbances during system contingency. Work is in progress to provide experimental results for a $2.2 \mathrm{KW}$ DFIG WECS laboratory prototype to validate the proposed methodologies.

\section{REFERENCES}

[1] G.abad, J.Lopez, M.A.Rodriguez, L.Marrroyo, G.Iwanski, ’'Doubly Fed Induction Machine,'IEEE press.

[2] S.S.sue, V.Kinnares K.S,K.Kleebbua,'Design and analysis of delta modulated PWM inverter with regulated output voltage for $1 \phi$ Induction Motor Drives," International Conference on Power system Technology Power con,2000,Vol.1,pp.317-320. 
Electrical \& Computer Engineering: An International Journal (ECIJ) Vol.7, No.1/2, June 2018

[3] S.F.Ghoreoshi and D.L.Allaire, "Adaptive Uncertainty Propagation for Coupled Multidisciplinary Systems”, AIAA Journal (2017).

[4] Mahidi Imani, UlissesBraga-Neto, "Particle filters for partially-observed Boolean dynamical systems". Automatica87 (2018): 238-250.

[5] M.H.Kheraluwala, Deepakraj M.Divan,’Delta Modulation Strategies for Resonant Link Inverters," IEEE Transactions on power electronics, vol.5, no.1, April.1990.

[6] J.W.Kimball, Philip T.Kren and Y.Chen," Hysteresis and delta modulation control of Converters in using Sensorless current mode," IEEE Transactions on power electronics,vol.21.no.4, July.2006.

[7] P.D.Ziogas, "The delta modulation technique in static PWM inverters, " IEEE Transactions on Industry Applications, vol.IA,no.2,Mar/Apr.1981.

[8] Ramdan Razali, V.Subbiah, M.A.Choudhury, R.Yusof, "Performance Analysis of Online Dual Slope Delta Modulated PWM Inverter," IEEE International Symposium on Circuits and Systems, vol.5, 2002.

[9] J.S.Kim, S.K.Sul, " New Control Scheme for AC-DC-AC Converter without DC Link Electrolytic Capacitor,” 24th Annual IEEE Power Electronics Specilists Conference, 1993, pp. 300-306.

[10] M.A.Rahman, J.E.Quaicoe, A.R.Esmail, M.A.Choudhury, "Delta Modulated rectifier-Inverter for Uninterruptible Power Supplies," International Telecommunications Energy Conference, Oct. 1986, pp. 445-449.

[11] M.A.Rahman, J.E.Quaicoe, M.A.Choudhury, "An Optimum Delta Modulation Strategy for Inverter Operation,” 17th Annual IEEE Power Electronics Specialists Conference, June. 1986, pp. 410-416.

[12] Carlos F.Christiansen, Marh Ines Valla, Claudio H Rivetta, "A Synchronization technique for Static Delta-Modulated PWM Inverters," IEEE Transactions on Industrial Electronics, vol.35, no.4, Nov. 1988.

[13] V. Blasko and V. Kaura, "A New Mathematical model and Control of a three phase AC-DC voltage source Converter," IEEE Transactions on Power Electronics, vol. 12, no. 1, pp. 116-123, Jan. 1997.

[14] Mahidi Imani, UlissesBraga-Neto, "Maximum-Likelihood Adaptive Filtering for Partially-Observed Boolean Dynamical Systems," IEEE Transactions on Signal Processing 65.2 (2017): 359-371. 